pearance was presented as if only large, sharply-defined nuclei existed in a granular and fibrillary basis-substance. From the examination of fresh similar specimens, it is probable that this appearance is due to the metlod employed in the examination of the tumor, the cell-protoplasm being excecdingly destructible.

Towards the sclerotic more of the fibrous tissue was to be found in the tumor, the bundles of cells were smaller, the individual cells also not so large. At this part, the fibres of the chorio-capillaris were apparently split apart by the advancing growth, and were seen to project upwards into the tumor, often containing small accumulations of pigment granules. At the very edge of the tumor in this region, at a point where it was not to be stated defimitely, whether one had to do with choroid or sclerotic, though probably with the former, lines of small, round cells were found to lie between delicate, more or less parallel, fibres. In a general way it might be asserted that an advance of the new-growth into the proper tissue of the sclerotic had not taken place.

As a whole, the tumor was quite vascular, the bloodvessels small, but numerous, the walls exceedingly thin.

The tumor having been sent away before the sections were thoroughly examined, those cuts which represent the retina in connection, show it to be so thoroughly changed that no elements characteristic of its structure could be found. The sections obtained were from that portion of the tumor, as seen in the first wood-cut, from which the segment had been cut away.

At the very surface of the tumor was seen a limiting membrane, beneatl which was a limited layer of cells, some six in depth. These cells were closely packed togrether, contained round, single-nuclei with nucleoli. The upper layers were apparently round, with delicate intercellular fibres; the lowest layer, that immediately bordering upon the spindle-cells of the tumor, was made up of anastomosing stellate cells, immediately surrounded by a considerable amount of hyaline intercellular substance, in which were occasional minute granules and very delicate fibrils. So far as this part alone of the tumor is concerned, a more myxomatous character was presented. Occasionally, also, in the same vicinity, resemblances to the structures of the glioma were seen.

From the fact, however, that these doviations from the character of the general growth were limited to the position of the retina, the preëxisting anatomical peculiarities of the same were probably the direct cause of the varied pictures.

In a case of sarcoma the prognosis is naturally grave. The disease is, of course, essentially malignant, yet if any exception exists to this as to other rules, the present should be an instance of one. Spindlecelled sarcoma progresses very slowly. In the case of our patient, the growth was of moderate size and strictly confined to the eyeball, the optic ncrve being healthy, and the orbital cavity free. General infection through the lymplatics or circulation is ordinarily preceded by an extension of the disease in the immediate vicinity, which had not here had time to take place.

Prof. Weber is referred to by Knapp* as reporting two cases of choroidal melanosis, on which he had operated, the one thirteen, the other twenty years before. Both patients were living. In a case of Prof. Dor's, reported by the same author, the disease, a spindle-celled sarcoma, made its appearanco in 1858 , and was operated on in 1860 , when the eye was in a state of glaucomatous inflammation, a period considered extremely unfavorable. No recurrence had taken place nine years later.

In the present case, the operation should have been performed as soon as the tumor was diagnosticated, the delay having been a mistaken kindness to the patient. It was, however, so short and the progress of the disease so inconsiderable that it is unlikely to have been a source of injury.

The drawings of the gross and microscopic appearances were made by Dr. Fitz on the block, thereby materially lightening the labor of the engraver. They speak for themselves.

H. D.

\section{CASE OF LEAD POISONING FOLLOWING THE USE OF A HAIR PREPARA'TION.}

By J. M. Crockxn, M.D., Provincetown.

Tre following case of lead palsy, from using a "Frair Preparation," may not be uninter esting. R. W., aged 55, laborer, was attacked with what appeared to be muscular rheumatism, affecting mainly the deltoid and other muscles of shoulders, last February. When first visited, ho was suffering from pains which he had felt more or less severely for a month or two. Both arms were in this manner crippled. Ordered cotton batting to affected parts, lemon-

\footnotetext{
* Die intrnocularen Geschwalste, p. 209.
} 
juice and opiates internally. Made quite a rapid recovery, but when seen in March following, he was suffering from an almost complete paralysis of extensor muscles of fingers and hands, with dropping of wrists. He could readily and forcibly grasp, but found difficulty in letting go. No lead lines about gums could be seen. Said he had had several attacks of colic within a few years. Tho water used for drinking purposes was obtained from a brick well, and stood in a wooden bucket. Ordinary cooking utensils were used in his family. Subsequently, upon inquiry, I discovered that for fifteen years had used a " hair renewer," made by himself of three teaspoonfuls lac sulphur and two teaspoonfuls sugar of lead to a pint of water. With this he had drenched his hair and scalp as often as once a week. Under use of iodide of potassium and galvanism has made a good recovery, the hair-dressing having, of course, been discontinued. The urine was not examined after treatment began. No colic siuce uso of sugar of lead was stopped.

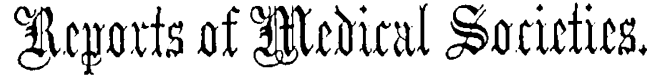

BOSTON SOCIETY FOR MFDICAL IMPROVEMENT. F. B. GREENOUGH, M.D., SECRETARX.

Nov. 27th, 1871.-Bright's Disease:-Dr. Fifield reported the case.

D. F., aged 58, Scotchman. Strong, tough, and always healthy. Forgeman by occupation. First applied for advice Oct. $26 \mathrm{th}$, complaining of violent pain in right hypochondrium, just beneath the false ribs. This pain was accompanied with vomitings of a greenish liquid, and the case was considered one of bilious colic. A pill consisting of a grain of opium was given; abstinence from all food and drink advised till the nausea and vomiting should cease.

27th.-Much better.

28th.- Has taken a dose of castor oil, and the bowels have been freely moved.

30 th.- Has returned to his work at the forge.

Nov. 6th.-Again complained of sovere pain in left hypochondrium, beneath the ribs, exactly in the same place as felt before in the right side. The vomitings consisted of the same liquid as before, the color a peculiar, light green. Pulse and tongue normal. The most careful examination of the parts where the pain is complained of, fails to reveal anything abnormal. No pain is caused by deep pressure over the situation of the kidney. Fine crepitation is heard at the base of left lung, which disappears after a few deep inspirations. No change in complexion of any part of the body. The patient declared that he passed no larger quantity of urine than he had ever done, and that he never rose in the night to urinate; that he had never been subject to headache or vomiting, and that his sight was perfectly clear. Same treatment to bo pursued as before. Asked that a portion of the urine might be saved.

7th.-Vomiting still present. Not so much pain. Impulse of the heart heavy, and widely extended. No murmur. Crepitation at base of the lung as before. Pulse 120. Temperature normal. This seemed so extraordinary that the accuracy of the instrument was doubted, but some experiments showed it to be correct. No urine had been saved. No medicine to bo given. A fow grains of calomel were placed on the tongue to check vomiting and perhaps move the bowels. Patient had not slept well.

8th.-Vomiting has ceased. No pain. No motion of bowels. Is very drowsy; can be roused and made to sit up and talk, but if allowed to lie down is instantly asleep. This condition is not the result of any opiate, as the patient has had none. Same crepitus at left base disappearing as before. No evidence of any effusion into any cavity of the body. No odema of the feet, hands or face. Patient had ruined the specimen of urine saved by spitting into it. On looking at the patient's mouth, he was found to be salivated from the calomel given yesterday. The suspicion that I had a case of Bright's disease to deal with became almost a certainty to me, for I havo never noticed such speedy salivation when this disease has not existed. Strong representations were made of the necessity of saving a specimen of the urine, and some was promised to be sent to me during the day. Three compound cathartic pills were ordered, to be followed by fluid extract of senna, if no motion was procured within five hours.

At 9 o'clock, the evening of the same day, I was sent for on account of the continued drowsy state of the patient, although ho had been restless at times during the day. The bowels had been well moved. $\Lambda$ specimon of the urine was now given me. Specific gravity 1015-one observer said 1012. Albumon present both by heat and acid. Rather small in quantity, but gives 